\title{
An Electron Paramagnetic Resonance Study of $\pi$ System Interaction in Dithiin Derivatives
}

\author{
Dolan H. Eargle, Jr., ${ }^{* \top}$ and Maria de Conceicão Ramos de Carvalho \\ Centro de Estudos de Quimica Nuclear e Radioquimica do Laboratório Quimico, Universidade de Coimbra, Coimbra, Portugal \\ (Received July 28, 1972)
}

\begin{abstract}
The anion radical of tetracyanodithiin (I) is shown to be a divalent sulfur system in which d-orbital participation in conjugation is negligible. The $g$ value $(2.0024)$ indicates that spin-orbit coupling is very small, and a molecular model shows that direct $\pi-\pi$ overlap of the ethylene moieties is probable. Other S-containing cation and anion systems are compared, including 2,5-diphenyldithiin (IV) and tetracyanothiophene (VI). Large cation $g$ value deviations and small anion deviations of $S$ heterocycles are contrasted with hydrocarbons.
\end{abstract}

Recent attempts to obtain a radical anion of a dithiin system, specifically thianthrene, in which the sulfur is in the divalent state have proven unsuccessful ${ }^{2,3}$ due to either decomposition of the material upon reduction or insufficient electron affinity (EA) of the compound under conditions of metal reduction. We wish to report a system that overcomes the previous difficulties, 2,3,5,6-tetracyanodithiin (I), and suggest some implications of the importance of its anion.

Two other anion radical systems involving electron conjugation through the sulfide system have been explored, dibenzothiophene (II) ${ }^{4,5}$ and thioxanthone (III), ${ }^{2,6}$ but these systems have the obvious drawbacks of containing other types of bonds linking the $\pi$ systems. In our search for a compound which could demonstrate conjugation of $\pi$ systems through a purely sulfide linkage we found that I possesses an EA sufficiently high for the required stability. Another compound, 2,5-diphenyldithiin, IV, was found to possess an insufficient EA for reduction; however, its cation radical was readily obtainable.<smiles>N#CC1=C(C#N)SC(C#N)=C(C#N)S1</smiles>

I<smiles>c1ccc(-c2csc(-c3ccccc3)c2)cc1</smiles>

IV

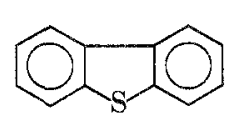

II<smiles>N#Cc1cc(C#N)c(C#N)nc1C#N</smiles>
$\mathrm{V}$

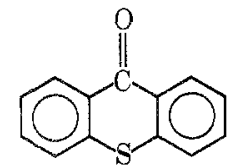

III<smiles>N#Cc1sc(C#N)c(C#N)c1C#N</smiles>

VI<smiles>[Y]C([Al])=c1ccc(=C([Al])C#N)cc1</smiles>

Experimental Section

Reductions of $\mathrm{I}$ and VI were by potassium metal in tetrahydrofuran at a temperature of $-80^{\circ}$. Dimethoxyethane proved an unsatisfactory solvent for $\mathrm{I}$, but serves well for VI.- ${ }^{-}$. Attempted oxidations of $\mathrm{I}$ in $\mathrm{H}_{2} \mathrm{SO}_{4}(96 \%$ or fuming) and in a mixture of $\mathrm{AlCl}_{3}$ in nitromethane were unsuccessful. Oxidation of IV was accomplished both in fuming $\mathrm{H}_{2} \mathrm{SO}_{4}$ and in the $\mathrm{AlCl}_{3}-\mathrm{CH}_{3} \mathrm{NO}_{2}$ mixture. Oxidation of VI was successful only in fuming $\mathrm{H}_{2} \mathrm{SO}_{4}$. Spectra were obtained on a Varian V-4502 spectrometer of the Universidade de Coimbra and a JEOLCO JESME instrument of the Universidad de Los Andes.

\section{Results and Discussion}

The esr spectra of I consisted of nine lines with approximately the appropriate intensity distribution for four equivalent nitrogen atoms. Although considerable evidence has been gathered concerning the ability of sulfide to transmit conjugative effects, ${ }^{7}$ this is the first instance in which an odd electron has been observed to be easily transmitted between $\pi$-electron moieties of an anion radical containing purely divalent sulfur linkages. ${ }^{8}$

The matter of which sulfur orbitals should be considered is of considerable interest. Several of the studies of the cations of dithiins point to the predominance of the involvement of $p$ orbitals, with a small contribution of the sulfur d orbital.9,10 Likewise, anions of sulfides (and sulfones) containing aromatic systems indicate some inclusion of the $d$ as well as $p$ orbitals (ref 7 and other pages therein). However, in nearly all these systems some deviation of the $g$ value from that of free spin $(g=2.0023)$ has been detected. This is probably due to some spin-orbit interaction of the electron with the sulfur nucleus. However, in this case (I), as in that of thianthrene disulfone, ${ }^{11}$ there is almost no deviation of the $g$ value of the anion from that of the free-spin value. ${ }^{12}$ This observation indicates that the spin-orbit interaction is very small indeed, and

(1) Present address, Departamento de Química, Universidad de los Andes, Mérida, Venezuela.

(2) E. T. Kaiser and D. H. Eargle, Jr., J. Amer. Chem. Soc., 85, 1821 (1963).

(3) E. T. Kaiser and D. H. Eargle, Jr., J. Chem. Phys., 39, 1353 (1963).

(4) R. Gerdll and E. A. C. Lucken, Proc. Chem. Soc., 144 (1963).

(5) D. H. Eargle, Jr., and E. T. Kaiser, Proc. Chem. Soc., 22 (1964).

(6) M. M. Urberg and E. T. Kaiser, J. Amer. Chem. Soc., 89, 1937 (1967).

(7) M. M. Urberg and E. T. Kaiser in "Radical Ions," E. T. Kaiser and L. Kevan, Ed. Interscience, New York, N. Y., 1968, pp 302-306.

(8) This observation does not apply to radical cations. See $G$. Vincow in ref 7 , pp 190-193.

(9) E. A. C. Lucken, Theor. Chim. Acta, 1, 397 (1963)

(9) E. A. C. Lucken, Theor. Chim. Acta, 1, 397 (1963),
(10) P. D. Sullivan, J. Amer. Chem. Soc., 90, 3618 (1968).

(11) D. H. Eargle, Jr, J. Phys. Chem. 73, 1854 (1969).

(12) Using biphenyl. - as a standard. 


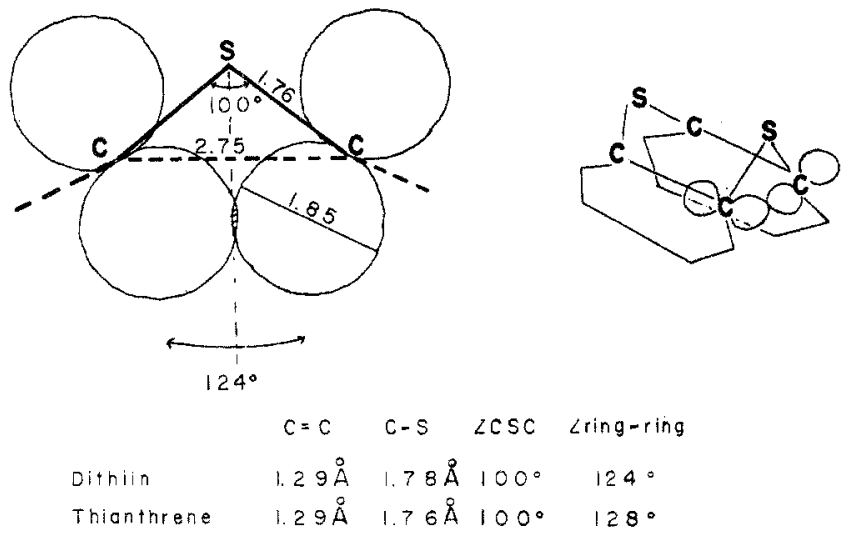

Figure 1. Models of dithiin and thianthrene drawn to scale using the molecular parameters of ref 16 and 17 . The Slater orbitals of the benzene rings are from Pauling. ${ }^{13}$ The ring carbonring carbon distance of $2.75 \AA$ may be compared, for example, to the distance of $2.83 \AA$ (between the 1 and $1^{\prime}$ carbons) found quite sufficient for ring-ring exchange of the odd electron in [2.2]paracyclophanes. ${ }^{14}$ Even with [3.3]paracyclophanes in which this distance is somewhat greater, direct $\pi-\pi$ overlap and rapid electron exchanges have been observed. ${ }^{15}$

on consideration of the HMO, there is theoretically no spin density on the sulfur atoms (in the nodal plant). (See Table I.)

Taking into account, then, this apparent lack of spin of the odd electron on the sulfur atoms and the facile spin exchange between the two dicyanoethylene moieties, we are led to the conclusion that electron transfer may be based on direct $\pi-\pi$ overlap of the two ethylene systems. This possibility has been advanced in the case of some sulfones by Urberg (ref 7, pp 315 and 319).

Consider now the models in Figure 1.13-15 The crystal structures of both thianthrene (VIII) and dithiin (IX) have been obtained, ${ }^{16,17}$ and constructing the model for these two molecules we find that the carbon-carbon $\pi$ orbitals of both systems have considerable direct overlap (as a matter of fact, quite sufficient to enable neglect of any contribution of sulfide orbitals). From this evidence we suggest that any "assistance" to conjugation in anions through the sulfur itself must be small, as is its contribution to the stability of the anion radical.

In addition, we should assume that the anion radicals of both these molecules do not assume planarity or even rapid conformational "flapping." In the thianthrene disulfone case this is not likely, considering the conformational stability of the anions of the cis- and trans-thianthrene disulfoxide isomers. ${ }^{3}$ The line widths observed for the anion of $\mathrm{I}(0.25 \mathrm{G})$ should be much larger, too, if conformational interconversion were occurring.

The observation of Urberg and Kaiser (ref 7, $p$ 303) that bis( $p$-nitrophenyl)sulfide anion preserves its electron on only one-half of the molecule also contributes valuable in formation to this problem. In this system, even though direct $\pi-\pi$ overlap is possible, it is not nearly as likely to furnish a good conjugative route for the electron, due to the free rotation of both aromatic rings.

We also attempted reduction of the disulfide, 2,5-diphenyldithiin (IV), in the hope that its two styryl groups might furnish sufficient stability (EA) along with the two $\mathrm{S}$ atoms for the odd electron. However, this experiment failed to realize a stable anion, no doubt due to the rotatability of the phenyl rings out of the planarity necessary for conjugation (Figure 2).

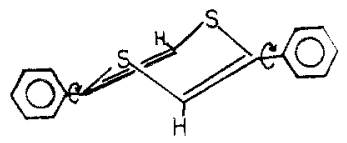

Figure 2.

TABLE I: Epr Spectral Data

\begin{tabular}{|c|c|c|c|c|}
\hline Compd & Radical & Hfs, G & $\begin{array}{l}\text { Spectral } \\
\text { width, G }\end{array}$ & $g$ value \\
\hline 1 & Anion & $a_{N}=1.6$ & 15.1 & 2.0024 \\
\hline IV & Cation & $a_{H(3,6)}=2.94$ & 9.8 & 2.0048 \\
\hline VI & Cation & $\begin{array}{l}a_{H\langle A r\rangle}=0.2 \\
\text { (Unresolvable) }\end{array}$ & $10.5 \pm 0.5$ & 2.0123 \\
\hline VI & Anion & $a_{\mathrm{N}}=1.10 \pm 0.02^{a}$ & 10.8 & 2.0020 \\
\hline
\end{tabular}

a This his was measured at $-40^{\circ}$. Further cooilng gave more hyperfine lines whose origins were not easily interpretable; however, they are probably from a slight variation of the ${ }^{14} \mathrm{~N}$ and ${ }^{13} \mathrm{C}$ couplings in the nitrile groups.

TABLE ॥

\begin{tabular}{|c|c|c|c|c|}
\hline \multicolumn{2}{|l|}{ Radical anion } & $a^{14} N(C \equiv N), G$ & Spectral width, $G$ & Ref \\
\hline $\begin{array}{l}\text { Tetracyano- } \\
\text { dithiin }\end{array}$ & 1 & 1.6 & 15.1 & This work \\
\hline $\begin{array}{c}\text { Tetracyano- } \\
\text { ethylene }\end{array}$ & VII & 1.56 & $\begin{array}{c}12.5 \\
\text { (excluding }{ }^{13} \mathrm{C} \text { ) }\end{array}$ & $a$ \\
\hline $\begin{array}{l}\text { Tetracyano- } \\
\text { pyridine }\end{array}$ & v & 1.1 & 15.4 & $b$ \\
\hline $\begin{array}{l}\text { Tetracyanoquino- } \\
\text { dimethane }\end{array}$ & $x$ & $\begin{array}{c}1.01 \\
\left(a_{H}=1.42\right)\end{array}$ & $\begin{array}{c}13.9 \\
\text { (excluding }{ }^{13} \mathrm{C} \text { ) }\end{array}$ & $c$. \\
\hline $\begin{array}{l}\text { Tetracyano- } \\
\text { thiophene }\end{array}$ & VI & 1.1 & 10.5 & This work \\
\hline
\end{tabular}

$a$ W. D. Phillips and J. C. Rowell, J. Chem. Phys., 33,626 (1960), ${ }^{b}$ M.T, Jones, J. Amer, Chem. Soc. 88, 5060 (1966). C P. H. H. Fischer and C. A. MCDowell, ibid., 85, 2694 (1963): M. T. Jones and W. R. Hertler, ibid., 86, $1881(1964)$

We did succeed, however, in obtaining the cation radical, which produced a very strong signal of only three lines, and although rather broad $(1.57 \mathrm{G})$, they showed only a slight tendency to split. ${ }^{18}$ This indicates that the odd electron density in the phenyl rings is small, and consequently would add little to the stability of an anion.

Several other observations were made in the spectra of I and IV.

(1) In the spectrum of I.-- were observed several lines of low intensity between the major ${ }^{14} \mathrm{~N}$ splittings. These can be attributed to ${ }^{13} \mathrm{C}$ splittings, especially in light of the expected high electron density on the cyano groups. No attempt was made at further interpretation.

(2) The $g$ value of IV.- was measured at 2.0048 and is not unlike those of other S-containing cations bearing large $g$ value deviations from 2.0023 (e.g., thianthrene., g $=2.0081) .{ }^{19} \mathrm{We}$ are thus confronted with a situation in

(13) L. Pauling, "Nature of the Chemical Bond," 2nd ed, Cornell University Press, Ithaca, N. Y., 1945, pp 164-189.

(14) A. Ishitani and S. Nagakura, Mol. Phys., 12, 1 (1967)

(15) F. Gerson and W. B. Martin, Jr., J. Amer. Chem. Soc., 91, 1883 (1969).

(16) P. A. Howell, R. M. Curtis, and W. N. Lipscomb, Acta Crystallogr., $7,498(1954)$

17) H. Lynton and E, G. Cox J Chem. Soc, 4886 (1956)

(18) See Table 1. Two or three small lines or shoulders were detectaole in each of the strong 3,6 proton lines. These are attributable to splittings from protons of the 2,5-phenyl groups.

(19) See G. Vincow in ret 7, p 190. 
which there are rather large $g$ value deviations in $\mathrm{S}$ heterocyclic cations, and very small deviations in the anions. This suggests very strongly that there is considerably more odd electron density on $\mathrm{S}$ in the cations than in the anions, and, therefore, different molecular orbitals are being utilized, or at least participation of $S$ orbitals is different and more pronounced in the cations (see ref $19, p$ 197).

In anions, we are utilizing a higher energy antibonding orbital in which, in our symmetrical molecules, the odd electron experiences a node at the $\mathrm{S}$ atom, while in cations we are robbing a bonding orbital, an orbital which "sees" the S nucleus strongly. Stone proposed ${ }^{20}$ (also see ref $7, p$ 164) that two effects are operative: one, that the filled orbitals of cation radicals are close in energy to those of the MO of the unpaired electron, giving rise to large cation $g$ values, and two, that the antibonding orbitals of anions generally possess MO coefficients of opposite signs on adjacent atoms, causing coupling with the filled orbitals and thus large anion $g$ values. In hydrocarbons, the second effect prevails, resulting in large $g$ values for the anions. However, it appears that in sulfur-containing heterocycles, the first effect appears to predominate, resulting in larger cation $g$ values.

Findings of $g$ values of 2.0020 and 2.0026 for the anions of tetracyanothiophene (VI) and tetracyanoquinodimethane (X) (Table II, ref c), respectively, and a large $g$ value of 2.0123 for the cation of VI lend considerable support to this theory.

(3) Two rather strong lines of equal intensity were observed at 8.84- and 11.96-G downfield from the center of the spectrum of IV.- when oxidized in fuming $\mathrm{H}_{2} \mathrm{SO}_{4}$ (the upfield lines were broadened). They were not present, however, in the $\mathrm{AlCl}_{3}-\mathrm{CH}_{3} \mathrm{NO}_{2}$ medium, and therefore must be attributable to a decomposition product in $\mathrm{H}_{2} \mathrm{SO}_{4} \cdot{ }^{33} \mathrm{~S}$ lines could not be detected.

At this point it should be of interest to compare the ${ }^{14} \mathrm{~N}$ hyperfine splitting (hfs) of I.- with those molecules of somewhat similar structures. A comparison of the ${ }^{14} \mathrm{~N}$ hfs constants should not be made without first considering the structures of these systems, although the splitting constants are rather similar. First, as pointed out by Jones (Table II, ref $b$ ), the proper MO picture of $\mathrm{V}$ should not be considered as possessing a node of zero spin density through the center, since the molecule is both planar and somewhat asymmetric. Nevertheless, we do find the hy- perfine splitting constant similar to that of I. Considering our model (Figure I) of the structure of I, and comments made earlier, we may, however, consider the anion radical of I somewhat similar to that of VII, if we neglect the S atom contributions. Thus, each half of the tetracyanodithiin would be considered as a half-TCNE. ${ }^{21}$ The similarity of the ${ }^{14} \mathrm{~N}$ hfs lends credence to this notion. Actually, it appears that slightly more electron density may be located on the nitrile groups of I than VII, judging from its greater hfs (Table II, ref $a$ ). ${ }^{22}$

The ${ }^{14} \mathrm{~N}$ hfs of $\mathrm{X}$ is, of course, somewhat diminished in comparison because of the electron density on the central benzene ring.

For this work we found it of interest to compare the anion of VI with that of I, since they are of rather different symmetry, although differing in composition by only one $\mathrm{S}$ atom. The anion of VI is planar, and considering that the total spectral width is almost $5 \mathrm{G}$ less than that of $\mathrm{I}^{-}$, a large amount of spin density is located within the thiophene ring.

Both the cation and anion spectra of this compound contained a small amount of an impurity which caused in the anion some distortion of a spectral wing. Its $g$ value was sufficiently different from that of VI, however, that interference was minimal

We have, then, in conclusion, observed that the tetracyanodithiin system can serve as a conjugative path for the odd electron in the anion radical, whether by use of divalent sulfur orbitals, or by direct $\pi-\pi$ overlap. We have also observed that the cation $g$ values of $\mathrm{S}$ heterocycles are considerably higher than those of corresponding or similar anions.

Acknowledgments. D. H. Eargle wishes to thank the Fundação Gulbenkian and the Instituto de Alta Cultura of Portugal for considerable support in this research.

(20) A. J. Stone, Mol. Phys., 6, 509 (1963); 7, 311 (1964)

(21) This observation is, of course, valid only if there is small spin densi ty on the ethylene carbons, otherwise we might have only a fortultous resultant of $\mathrm{C}-\mathrm{C} \equiv \equiv N$ spin polarization. However, spin density on each ethylene carbon is $<0.10$.

(22) We have not attempted MO calculations of 1.- because of the indeterminacy of including $S$ atom $p$ and $d$ orbital involvement and simultaneous $\pi-\pi$ overlap. Indeed, it does not appear to be necessary to do so, in light of the similarity of the hyperfine spittings of 1.-- and VI1.- and the adequacy of the structural model shown in Figure 1. 